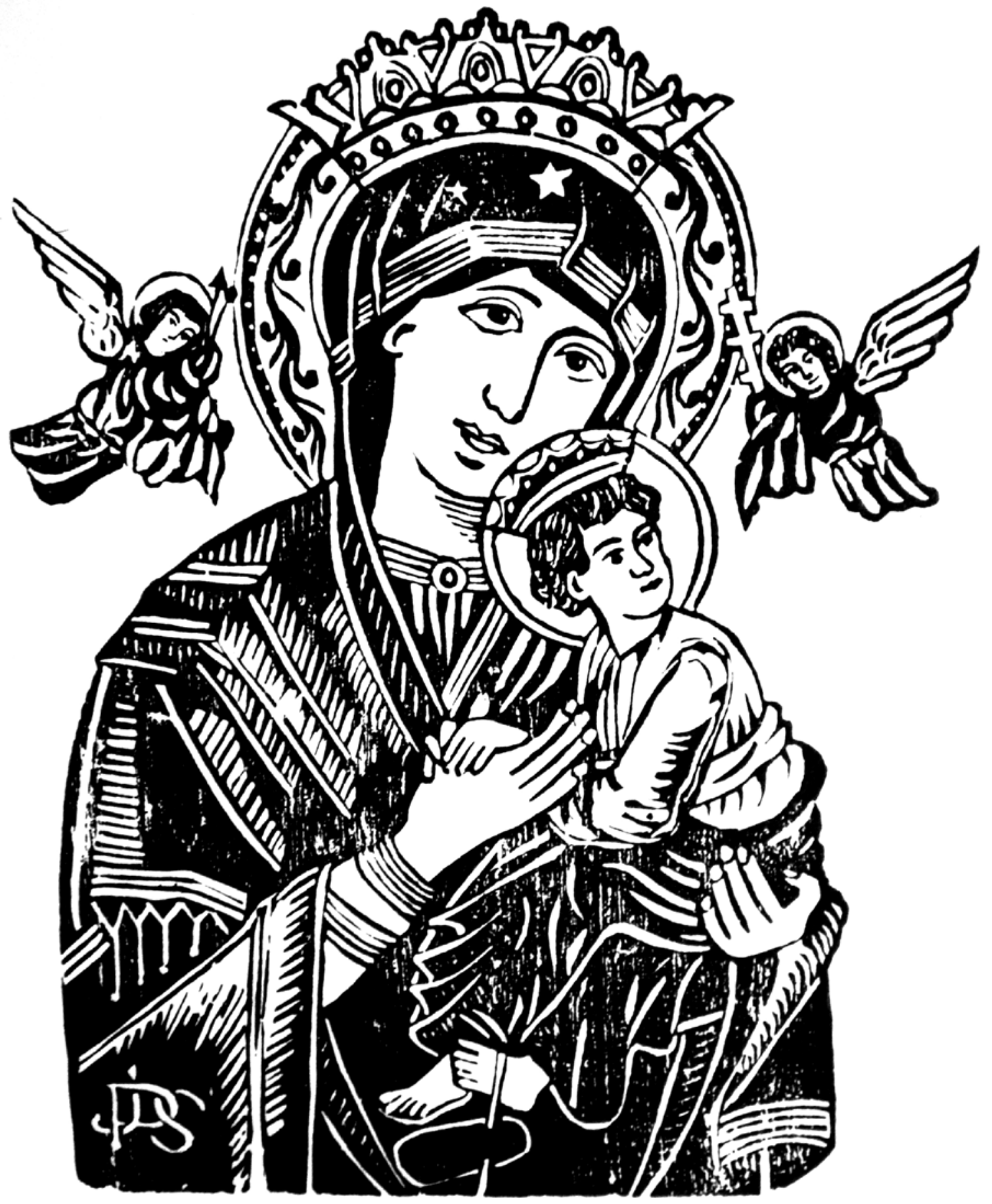




\section{Do mercado ao museu: a legitimação artística da gravura popular}

EVERARDO RAMOS

Resumo

Se todas as categorias de arte passam por variados processos de legitimação, existe uma, em particular, onde a questão da legitimidade é fundamental, por ser determinante de sua própria existência: a arte popular, que só existe realmente, como categoria artística, a partir do momento em que é reconhecida pelas instâncias oficiais. O presente trabalho analisa o processo de legitimação artística da gravura popular, produção que se desenvolve às margens do sistema oficial, como ilustração dos folhetos de cordel vendidos em mercados públicos, antes de se tornar uma categoria privilegiada da "arte popular", colecionada e exposta em museus nacionais e internacionais. 


\section{Abstract}

Once all artistic categories undergo different processes of legitimacy, there is one in particular, in which the issue of legitimacy is fundamental for determining its very existence: popular art, which only begins to exist as an artistic category from the moment it is acknowledged by official instances. The current paper analyzes the process of artistic legitimacy of popular engraving, whose production is developed on the margins of the official system, as illustrations in cordel booklets to be sold in public markets and then to become a privileged category of "popular art", collected and exhibited in both national and international museums. 
Recentemente, uma pesquisa de grande extensão trouxe à tona um tema muitas vezes esquecido pela História da Arte: o da legitimação artística. Partindo de perguntas como "o que legitima um artista?" ou "como se dá e o que representa essa legitimação?", Clarissa Diniz mostrou de que maneira se formam espaços específicamente "artísticos" no vasto campo do conhecimento e do fazer humanos, a partir de variados processos que vão da autolegitimação à legitimação por diferentes instâncias (instituições, mercado, especialistas, mídia, público, ensino $)^{1}$. Revela, portanto, que o conceito de "arte", pelo menos no contexto contemporâneo, é tão dependente da idéia de transcendência das obras e dos artistas, quanto de complexas relações de ordem social, cultural, política e econômica.

Todas as categorias de arte estão submissas a essa lógica. No entanto, existe uma, em particular, onde a questão da legitimidade tem uma importância ainda maior, por ser determinante de sua própria existência. Trata-se da arte popular, outro grande tema frequentemente esquecido pela História da Arte, que só existe realmente, como categoria artística, a partir do momento em que passa por um processo de legitimação. E, sempre, de legitimação por instâncias oficiais, externas ao universo onde as obras são originalmente produzidas e consumidas: ao contrário dos artistas estudados por Clarissa Diniz, o criador popular nunca se autodenomina "artista" antes de ter sido reconhecido como tal, fora do seu meio.

Mas como se dá o processo de legitimação da arte popular? Quais são seus agentes e significados, e que repercussões ela traz para as obras e os artistas? O presente trabalho tentará responder a essas perguntas a partir do estudo da gravura popular, produção que surge e se desenvolve às margens do sistema oficial, como ilustração dos folhetos de cordel vendidos em mercados públicos, antes de se tornar, a partir de um determinado momento, uma categoria privilegiada da "arte popular", colecionada e exposta em museus nacionais e internacionais. Uma análise cuidadosa desse momento de transição mostrará que a legitimação artística das produções populares não passa apenas pela aquisição do estatuto de "obra de arte", envolvendo também questões complexas, como a influência de correntes ideológicas no cenário cultural brasileiro.

\section{A descoberta da gravura popular}

No Brasil, as primeiras manifestações de interesse do mundo "letrado" pela gravura popular acontecem em meados do século XX. Em 1949, em um artigo publicado na imprensa de Maceió, o fol- 
2. As informações e a citação desse parágrafo provêm do álbum Coleção Théo Brandão. Xilogravuras Populares Alagoanas (1973). Segundo esse texto, o artigo de Théo Brandrão, intitulado "As Cheias de Alagoas e a Literatura de Cordel,' foi publicado no Jornal de Alagoas, em junho de 1949.

3. As informações desse parágrafo provêm de Suassuna (1952), Machado (1960) e catálogo da exposição Arts primitifs et modernes brésiliens (1955). O álbum editado por Aluísio Magalhães, de que não encontramos nenhum exemplar, é citado no album Xilogravura Popular (1965) e em Suassuna (1969).

4.. Cf. documentos diversos pedidos de reembolso, faturas, prestação de contas - relativos às viagens feitas por Lívio Xavier Júnior e Floriano Teixeira em 196o, e conservados nos arquivos do Museu de Arte da Universidade do Ceará, em Fortaleza, na pasta Documentos. Prestação de contas. Outras informações foram obtidas em entrevistas com Lívio Xavier Júnior, em 2000 e 2003. clorista Théo Brandão chama a atenção para uma gravura de José Martins dos Santos, poeta que se tornou xilógrafo para realizar, de maneira improvisada, as ilustrações de seus folhetos de cordel. No mesmo ano, os dois homens se conhecem num mercado da cidade, ocasião em que Brandão pede autorização para publicar a mesma gravura em seu livro Folclore de Alagoas. Três anos depois, em 1952, o folclorista consegue "de José Martins dos Santos não somente o clichê anteriormente emprestado, mas vários outros de sua autoria, que serviam de capa a folhetos seus ou de seus colegas de arte, para reproduzi-los em pranchas e expô-los na mostra de arte folclórica alagoana", segundo seu próprio depoimento ${ }^{2}$.

Em seguida, o movimento se estende ao Recife, onde a gravura popular desperta o interesse de um grupo de artistas e intelectuais ligados ao Teatro do Estudante de Pernambuco. Em 1952, o jovem escritor Ariano Suassuna publica um longo texto sobre a ilustração de folhetos de cordel, numa reportagem ilustrada que ocupa toda a primeira página do Diário de Pernambuco, o mais tradicional dos jornais locais. No ano seguinte, o pintor Aluísio Magalhães "descobre” a gráfica de João José da Silva, importante editor de cordel, e organiza um álbum com gravuras utilizadas em seus folhetos, publicando-o com o apoio do Departamento de Documentação e Cultura da Cidade do Recife. Dois anos mais tarde, em 1955, o colecionador Abelardo Rodrigues envia algumas dessas gravuras ao Musée d'Ethnographie de Neuchâtel, na Suíça, para a maior exposição de arte brasileira até então realizada no exterior ${ }^{3}$.

Enfim, no Ceará, o interesse pela gravura popular parte de uma instituição pública, a Universidade do Ceará, no momento de criação de seu museu de arte regional, em Fortaleza. Em 1960, dois funcionários da instituição vão a Juazeiro do Norte, na região do Cariri, para obter cópias das ilustrações utilizadas por José Bernardo da Silva, o maior editor de cordel do Estado. Na gráfica deste, no entanto, encontram um verdadeiro "tesouro": caixas inteiras contendo antigas xilogravuras que deixaram de ser utilizadas nos folhetos, tornando-se obsoletas. Com a anuência do editor, os dois funcionários compram todo o material e levam-no para Fortaleza, onde passam a fazer parte do acervo do Museu de Arte da Universidade do Ceará, constituindo a primeira coleção pública no gênero ${ }^{4}$.

Entusiasmada com a compra, a Universidade envia seus funcionários à procura de novas obras, desta vez junto aos outros grandes editores de cordel da época, Manoel Camilo dos Santos, em Campi- 
na Grande, e João José da Silva, em Recife. Ambos também vendem suas xilogravuras, apesar destas ainda serem utilizadas nas reedições dos folhetos. Vale ressaltar que essa transação contrasta muito com a atitude dos intelectuais de Recife, que sempre tiveram o cuidado de devolver as matrizes tomadas de empréstimo aos editores populares, depois de utilizá-las em suas próprias ações, como tinha feito Théo Brandão em Maceió. Em uma carta ao organizador da exposição de Neuchâtel, por exemplo, Abelardo Rodrigues sugere que seja feita uma plaqueta ilustrada com as obras enviadas de Recife, mas acrescenta: "Pediria, apenas, a devolução das matrizes, logo após a impressão, pois os folhetos populares ilustrados por aquelas xilogravuras ainda estão em franca circulação, sendo frequentes as pequenas reedições"s. Assim, quando a Universidade do Ceará compra as matrizes dos editores populares, retirando-as de seu meio natural, são bastante criticados pelos intelectuais recifenses ${ }^{6}$.

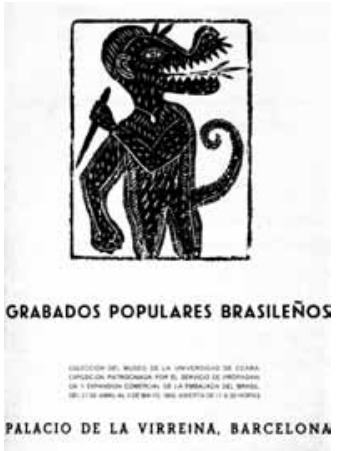

$-1$.

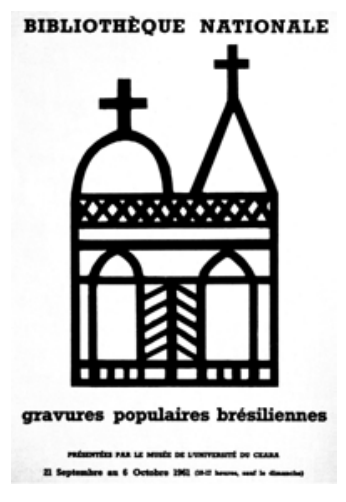

Seja como for, os cearenses começam rapidamente a valorizar sua nova coleção, no Brasil e no exterior. Ainda em 1960, enviam uma seleção de obras ao Museu de Arte Moderna de São Paulo, para a exposição Gravuras Populares do Nordeste, a primeira inteiramente dedicada ao tema, já que as exposições anteriores - em Maceió (1952) e em Neuchâtel (1955) - incluíam outras categorias de obras. A iniciativa mais importante, que iria associar definitivamente o nome da Universidade do Ceará à promoção da gravura popular brasileira, é, no entanto, a exposição que apresenta em diversas cidades da Europa e em Minneapolis, nos Estados Unidos, entre 1961 e 1962, em instituições tão prestigiosas quanto a Bibliothèque Nationale de Paris, o Palacio de la Virreina de Barcelona (Figura o1 e 02), o Museu de Arte Contemporáneo de Madri e o Kunstmuseum
Figura o1

Cartaz da exposição Gravures populaires brésiliennes, Bibliothèque Nationale, Paris, 1961, $50 \times 32,5 \mathrm{~cm}$ (Col. Museu de Arte da Universidade do Ceará, Fortaleza).

Figura 02.

Cartaz da exposição Grabados populares brasileños, Palacio de la Virreina, Barcelona, 1962, $49 \times 34,5 \mathrm{~cm}$ (Col. Museu de Arte da Universidade do Ceará, Fortaleza).

5. Cf. carta de Aberlardo Rodrigues a Raul Bopp (embaixador do Brasil na Suíça e principal organizador da exposição em Neuchâtel), datada do Recife, em 26 de julho de 1955, e conservada nos arquivos do Museu da Imagem e do Som de Pernambuco, no Recife, na pasta Abelardo Rodrigues.

6. Informação de Lívio Xavier Júnior, um dos funcionários da Universidade do Ceará envolvidos na questão, em entrevista realizada em 2000. 
7. Documentos diversos (catálogos, convites e cartazes), conservados nos arquivos do

Museu de Arte da Universidade do Ceará, em Fortaleza, indicam as seguintes exposições: Gravures populaires brésiliennes (Cabinet des estampes de la Bibliothèque nationale, Paris, 21 de setembro-6 de outubro de 1961) Brasilianische Imagerie Populaire (Kunstmuseum, Basiléia, 28 de outubro-17 de dezembro de 1961) ; Gravuras Populares do Nordeste Brasileiro (Sociedade Nacional de Belas Artes, Lisboa, dezembro de 1961) ; Grabados populares brasileños (Museo de Arte Contemporáneo, Madri, 2-14 de abril de 1962 ; Palacio de la Virreina, Barcelona, 27 de abril-5 de maio de 1962 ; Facultad de Filosofia y Letras, Sevilha, datas ignoradas) ; Volkstümliche Holzschnitte aus NO. Brasilien (Museum für Völkerkunde, Viena, março de 1962) ; Brazilian Folk Art : Yesterday and Today (Walter Art Centrer, Minneapolis, 17 de março-22 de abril de 1962).

8. João Cabral de Melo Neto, poeta-diplomata que colaborou com as exposições realizadas na Espanha (inclusive escrevendo o texto introdutório do catálogo em espanhol), afirma em uma carta para um funcionário da

Universidade do Ceará: "Vão junto alguns recortes de jornal sobre a exposição. Tratam da de Barcelona. $O$ êxito ali foi enorme" - cf. carta datada de 17 de maio de 1962, destinada a Lívio Xavier Júnior e conservada pelo destinatário. Sobre a repercussão na imprensa brasileira, veja-se, por exemplo: Machado (196o) e o artigo anônimo "Arte Brasileira em Portugal" (1962). da Basiléia (Suíça)7. Tais exposições têm grande repercussão, inclusive no Brasil, consolidando definitivamente a gravura popular como uma importante categoria da arte brasileira ${ }^{8}$.

Assim, em meados do século XX, a história da gravura popular toma um rumo completamente diferente daquele que vinha seguindo anteriormente. Desde os anos 1900, essa gravura nunca tinha mudado de estatuto, destinando-se exclusivamente a ilustrar impressos modestos e de grande circulação, como os folhetos de cordel. Com a intervenção dos intelectuais, ao contrário, as mudanças se multiplicam. Primeiro, as obras são utilizadas em contextos completamente novos: impressas em folhas independentes, para participarem de exposições, ou publicadas em albuns ilustrados. Em seguida, as próprias matrizes gravadas são retiradas de seu meio de origem - as gráficas populares - para enriquecer o acervo de museus. Existindo por ela mesma, e não mais em função da ilustração dos folhetos de cordel, a gravura popular adquire, portanto, o estatuto de "obra de arte" e, mais ainda, de arte celebrada a nível nacional e internacional.

Daí por diante, sua história não poderia mais ser a mesma.

\section{(De)Formação de uma categoria artística}

A intervenção do mundo letrado não se limita, porém, a transformar a gravura popular em categoria artística: ela também define esta categoria, pela própria maneira como a estabelece. De fato, as diversas ações de promoção e valorização da gravura popular - artigos na imprensa, exposições, publicação de álbum e constituição de coleção - têm como objeto apenas um tipo de obra: a xilogravura dos folhetos de cordel. Técnica e função constituem, portanto, noções identificadoras da nova categoria artística, guiando as atitudes e as reflexões dos intelectuais da época. Com o passar do tempo, tais noções iriam inclusive cristalizar-se, fazendo com que, nos dias de hoje, a expressão "gravura popular" se confunda frequentemente com a palavra "xilogravura" e com a categoria "ilustração de folheto de cordel", como se todas fossem sinônimos.

Confrontando esta definição com o estudo das próprias obras, percebe-se, no entanto, que ela não traduz completamente a realidade dos fatos, tal como eles se apresentavam aos artistas e intelectuais que começaram a se interessar pela gravura popular. Se é certo que a gravura popular se desenvolve nos folhetos de 
cordel da primeira metade do século XX, suas origens se encontram em outros tipos de impressos, bem mais antigos. De fato, como pudemos demonstrar em outros estudos, essa gravura surge nos jornais e nas revistas do século XIX, onde já apresenta muitas características das futuras ilustrações de cordel, seja em termos de técnicas, de formas ou de princípios de criação. Quando os artistas e intelectuais "descobrem" as imagens dos folhetos, acreditam, porém, que estão diante de algo completamente novo, esquecendo de explorar com mais cuidado o que poderia ser anterior. Na verdade, para se compreender verdadeiramente a gravura popular, é preciso inseri-la na vasta e complexa história das ilustrações de impressos de grande circulação, que começa com os primórdios da imprensa brasileira, na primeira metade do século XIX ${ }^{9}$.
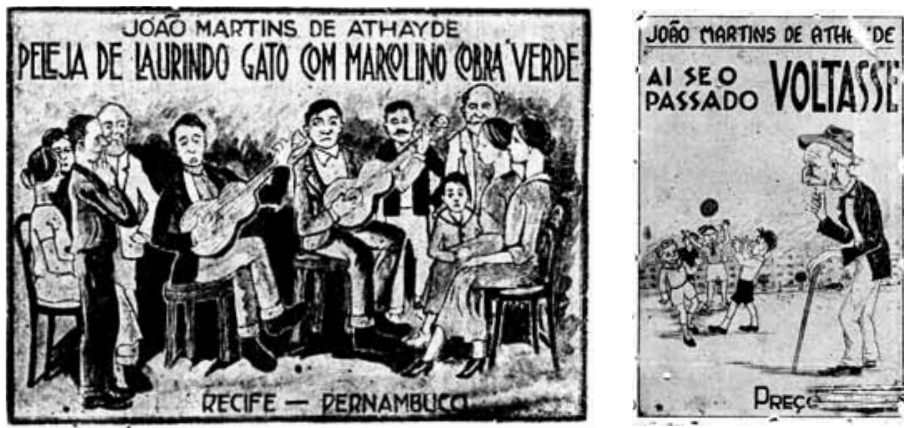

Figura 03 - Folheto de cordel com zincogravura atribuída a Antônio Avelino da Costa: Ai se o passado voltasse, Juazeiro do Norte, Tip. São Francisco, 1954, c. 15 x $11 \mathrm{~cm}$ (col. Biblioteca Central Zila Mamede-UFRN, Natal).

Figura 04 - Folheto de cordel com zincogravura atribuída a Antônio Avelino da Costa: Peleja de Laurindo Gato com Marcolino Cobra Verde, Juazeiro do Norte, Tip. São Francisco, 1951, c. 15 x 11 cm (col. Biblioteca Central Zila Mamede-UFRN, Natal).

O equívoco da segunda idéia de base, que associa a gravura popular apenas à técnica da xilogravura, é, porém, mais significativo. Através de uma análise exaustiva, pudemos concluir que os folhetos publicados no Recife, o maior centro de edição de cordel da primeira metade do século XX, são majoritariamente ilustrados, não por xilogravuras, mas por zincogravuras, que reproduzem imagens fotográficas e desenhos de artistas autodidatas. Dentre estes, destaca-se Antônio Avelino da Costa, autor de quase todas as ilustrações de João Martins de Athayde, o principal editor da época (Figura 03 e 04). A zincogravura era, inclusive, o tipo de ilustração preferido do público tradicional
9. Cf. Ramos (2005a) e outro estudo nosso, atualmente no prelo: "Origens da Imprensa Ilustrada Brasileira (1820-1850): Imagens esquecidas, Imagens Desprezadas", a ser publicado na Revista Escritos, $n^{\circ} 3$, pelas Edições Casa de Rui Barbosa, no Rio de Janeiro. 
10. Para uma análise detalhada das diferentes formas de ilustração de cordel, cf. Ramos (2005b e 2008b).

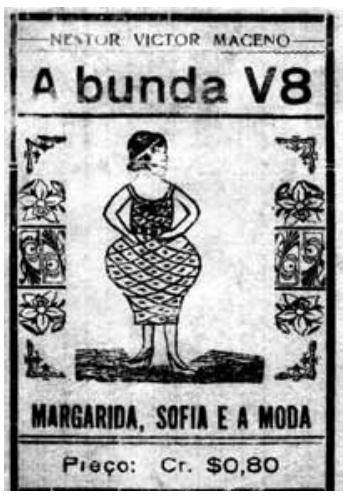

Figura 05 Folheto de cordel com xilogravura anônima: A bunda V8. Margarida, Sofia e a moda, Juazeiro do Norte, Tip. São Francisco, 1945, c. $15 \times 11$ cm (col. Biblioteca Central Zila Mamede-UFRN, Natal).

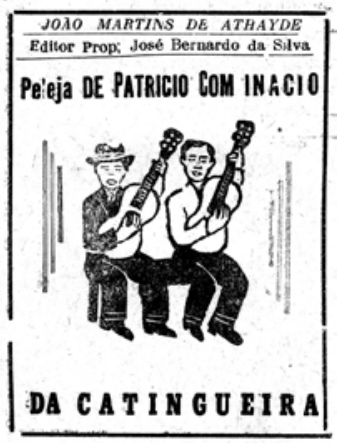

Figura o6 Folheto de cordel com xilogravura anônima: Peleja de Patricio com Inacio da Catingueira, Juazeiro do Norte, Tip. São Francisco, 1952, c. $15 \times 11 \mathrm{~cm}$ (col. Biblioteca Central Zila Mamede-UFRN, Natal). de folhetos, contribuindo muito para o enorme sucesso da literatura de cordel. Já a xilogravura, era utilizada principalmente nas cidades do interior, como Juazeiro do Norte, no Ceará, onde gráficas rudimentares não permitiam praticar técnicas mais elaboradas, como era o caso no Recife..$^{10}$ (Figura 05 e o6)

Quando os intelectuais começam a se interessar pelas ilustrações de cordel, a partir do final dos anos 1940, têm diante de si, portanto, as duas categorias de obra: xilogravura e zincogravura, facilmente encontradas nos folhetos da época. Porque, então, privilegiam a primeira, em detrimento da segunda, no processo de promoção e valorização da gravura popular?

A primeira razão dessa preferência diz respeito à técnica empregada na realização das obras. A xilogravura, como se sabe, corresponde à maneira mais antiga e simples de se fazer uma imagem multiplicável, constituindo um processo completamente manual, desde a elaboração do desenho até sua gravação na madeira. A zincogravura, por sua vez, surge com a Revolução Industrial do século XIX, constituindo um processo híbrido: o desenho é feito à mão, sobre uma folha de papel, mas a gravação se dá por processos fotomecânicos, através de equipamentos especiais. Privilegiar a primeira técnica, em detrimento da segunda, revela, portanto, dois preconceitos surgidos com os folcloristas do século XIX: o de associar o "popular" exclusivamente ao que é artesanal e o de considerar o artesanal como mais "autêntico" do que os produtos da civilização industrial.

Interessa notar, também, que esse duplo preconceito deformou, muitas vezes, a visão da história das ilustrações de cordel. Por exemplo, os intelectuais consideravam que a raridade dos folhetos ilustrados por xilogravura, no Recife, não era algo natural, mas a consequência do uso recente e cada vez maior da zincogravura (contendo desenho ou fotografia), que se impunha com o avanço da civilização industrial. Ora, como dissemos anteriormente, isso não é absolutamente verdade: no Recife, onde existiam as gráficas mais modernas do Nordeste, a zincogravura sempre foi mais importante que a xilogravura. A interpretação do jornalista e crítico de arte Lourival Gomes Machado, que descobre as ilustrações de cordel juntamente com Aluísio Magalhães, nos mercados e gráficas da cidade, é, no entanto, exatamente oposta:

[as xilogravuras] já desapareciam, nos mostruários dos cantores-vendedores, sob o maior número de folhetos capeados por 
péssimas reproduções de fotos tiradas de revistas de cinema, ou de oleogravuras sulpicianas (MACHADO, 1960 p.6).

Os xilógrafos populares já cediam inteiramente seu território físico - as capas dos folhetos - à fotografia imbecil dos cartões postais, à pobre caricatura das revistas litorâneas, à romântica reprodução das cenas de filmes (MACHADO, 1961 p.6).

O equívoco aumenta quando a Universidade do Ceará compra, em Juazeiro do Norte, xilogravuras que - elas sim - tinham sido efetivamente substituídas pelas zincogravuras compradas por José Bernardo da Silva a João Martins de Athayde, do Recife, quando este decidiu parar de trabalhar, em 1949. Convencidos de que, em toda parte, a técnica artesanal da madeira era necessariamente anterior à técnica mecânica do zinco, os intelectuais fazem um amálgama de situações completamente diferentes, confundindo a história da produção gráfica num grande centro como Recife e numa pequena cidade do interior, como Juazeiro do Norte. Vale notar, por outro lado, que essa confusão também serve para legitimar a própria compra das matrizes de madeira encontradas nas gráficas populares, consideradas "em extinção": quando a Universidade do Ceará inaugura essa prática e é bastante criticada, Lourival Gomes Machado toma sua defesa, afirmando que "salvou-se, ao menos para a história, uma arte em franco processo de desaparição” (MACHADO, 1961 p.6).

Enfim, os preconceitos e equívocos se consolidam quando a gravura popular brasileira é comparada à sua congênere européia, durante as exposições realizadas pelo Museu de Arte da Universidade do Ceará, em diferentes países do Velho Mundo. Na Suíça, por exemplo, Hanspeter Landolt, diretor do Kunstmuseum da Basiléia, afirma:

As xilogravuras [brasileiras], com sua linguagem concisa, de convenção, são autenticamente primitivas, como eram as xilogravuras do século XV na Europa central. Como estas, aquelas estão, por sua espontaneidade, condenadas à morte pelo progresso: enquanto na Europa, a primeira gravura foi eliminada e substituída pela gravura artística "acadêmica", os gravadores brasileiros, por causa da visão tecnicista do público e da oferta de revistas coloridas de baixo preço, se vêm acossados ao muro. Que esse pedaço de arte popular verdadeira tenha conseguido manter-se até hoje faz dele um vestígio muito interessante, no nosso mundo que se precipita impetuosamente em direção a uma civilização tecnicista e uniforme. ${ }^{11}$
11. Cf. catálogo da exposição Brasilianische Imagerie Populaire (1961), p. 4. Agradecemos a JeanPierre Gavignet pela tradução, em português, do texto original em alemão. 


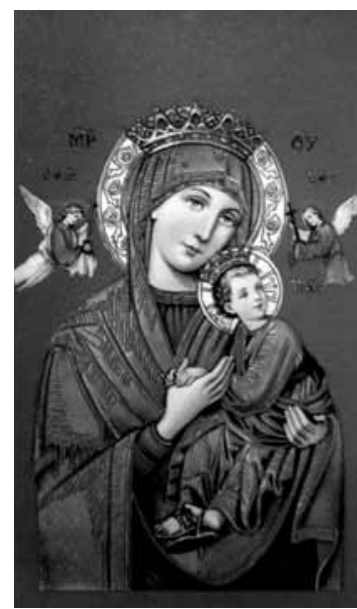

Figura 07 Santinho: Nossa Senhora do Perpétuo Socorro, São Paulo, Paulinas, s. d., $9 \times 7 \mathrm{~cm}$ (col. Everardo Ramos, Natal).
Assim, projetando no Brasil do século XX uma situação da Europa do século $\mathrm{XV}$, o mundo letrado cristaliza a idéia de que a arte popular corresponde exclusivamente à técnica artesanal e que, por isso mesmo, constitui uma categoria constantemente ameaçada pelo avanço da civilização. Considerada como o precioso "vestígio" de uma época remota e idealizada, tendo resistido bravamente às consequências nefastas do progresso material e da industrialização, a xilogravura aparece, portanto, como a técnica mais autêntica e representativa, a única digna de figurar nas coleções, exposições e reflexões que legitimam artisticamente a categoria "gravura popular".

Mas a técnica não é a única razão da preferência pela xilogravura, em detrimento da zincogravura. Quando analisam as imagens que ilustram os folhetos de cordel, os intelectuais sempre chamam a atenção para as características estilísticas que, em sua opinião, fazem sua originalidade: a composição extremamente simples, a representação bidimensional e as formas esquemáticas, estilizadas. Ora, ao contrário das xilogravuras que fundamentam este postulado (Figura o5 e o6), as zincogravuras apresentam frequentemente desenhos bastante elaborados, representados em três dimensões e com traços "acadêmicos", no estilo das caricaturas (Figura 03 e 04). Assim, as obras gravadas em zinco são condenadas, não somente por serem realizadas por meios mecânicos, mas também por apresentarem formas que Lourival Gomes Machado define, de maneira sumária e pejorativa, como "linguagem sub-acadêmica dos menos fortes" (MACHADO, 1961 p.6).

Deve-se acrescentar, porém, que essa apologia das formas estilizadas não exclui apenas a zincogravura, do processo de legitimação da "gravura popular". De fato, uma análise cuidadosa revela que ela também exclui um tipo especial de xilogravura, bastante diferente da xilogravura "primitiva" privilegiada pelos meios letrados: enquanto estas apresentam desenhos rústicos, gravados com traços grosseiros, aquelas apresentam imagens de tipo "acadêmico", copiadas de outros suportes e gravadas sobre a madeira com grande fineza. Vários ilustradores de cordel realizam esse gênero de gravura, destacando-se João Pereira da Silva, o pioneiro da xilogravura de cordel em Juazeiro do Norte, que manifesta um grande talento para entalhar linhas extremamente finas, complexas e delicadas, que reproduzem todos os detalhes dos motivos copiados, inclusive efeitos de textura e volume (Figura o7 e o8). 


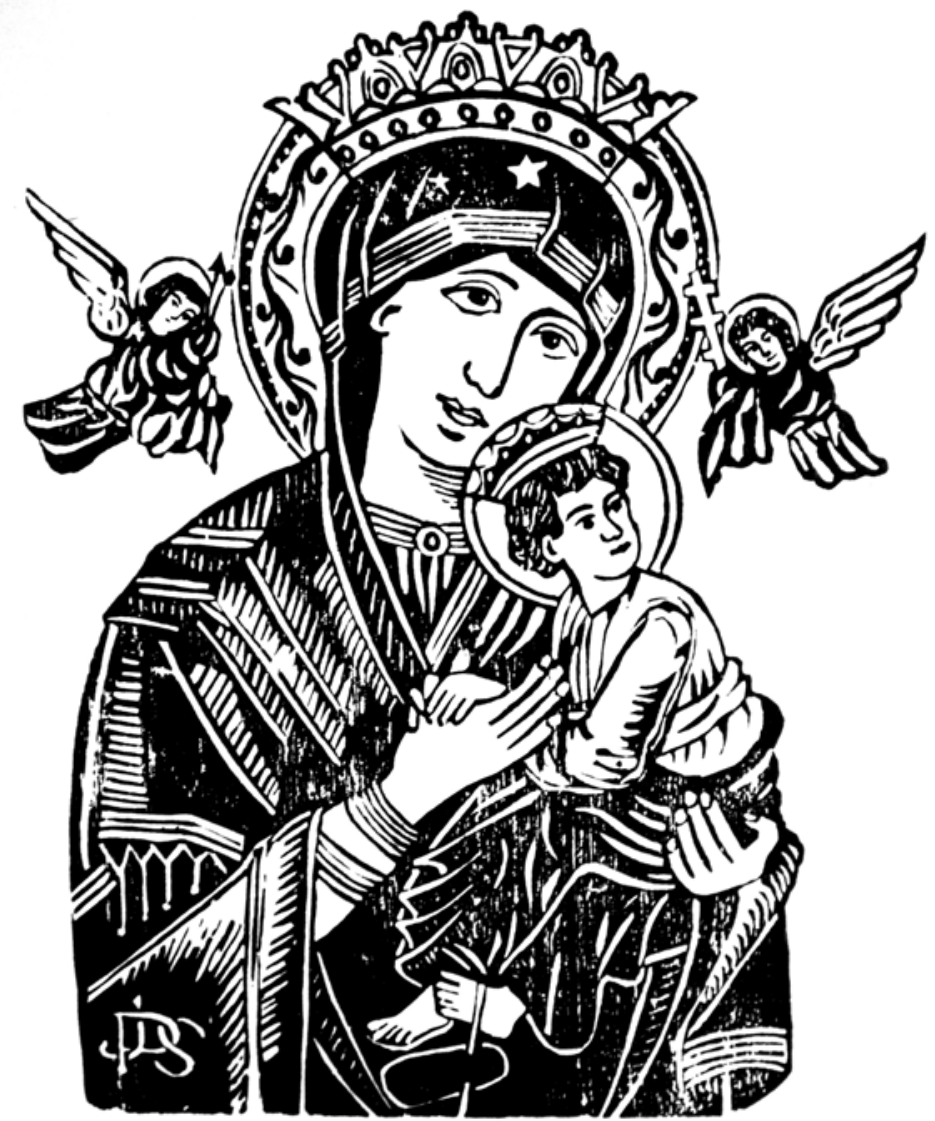

Figura o8 - Xilogravura de João Pereira da Silva para folheto religioso não identificado, 8,5 × 6,8 cm (col. Geová Sobreira, Brasília).

Como os intelectuais e o público letrado encaram essas gravuras? As opiniões sobre a obra de João Pereira da Silva, bem como sua própria história de vida, são reveladoras de uma condenação que, sem ser explícita, é generalizada. No catálogo da exposição apresentada no Museu de Arte de São Paulo, em 196o, Antônio Martins Filho, Presidente da Universidade do Ceará, explica:

Trabalho verdadeiramente anônimo e até certo ponto considerado acessório de pouca ou nenhuma importância para o acabamento geral da peça "literária" [ele se refere aos folhetos de cordel], [a xilogravura] dispensa a assinatura nos melhores exemplares; alguns artistas, talvez exatamente por este motivo, não os mais genuínos, dão-se ao requinte erudito de uma rubrica, tal como o gravador João Pereira da Silva. ${ }^{12}$
12. Cf. catálogo da exposição Gravuras Populares do Nordeste (1960), s. p. 
Dentre os gravadores representados nessa exposição, João Pereira da Silva não é, porém, o único a assinar seus trabalhos, sendo acompanhado, nessa prática, por Damásio Paulo, Walderêdo Gonçalves e Antônio Batista Silva: porque, então, somente o primeiro é considerado como "menos genuíno"?

A discriminação em relação ao trabalho de João Pereira da Silva só se manifesta claramente, porém, depois das primeiras exposições de gravura popular, quando a Universidade do Ceará decide relançar a produção de xilogravuras em Juazeiro do Norte. Para isso, encomenda novas obras aos diversos xilógrafos da cidade, exceto, justamente, a João Pereira da Silva. Inocêncio da Costa Nick (mais conhecido por Mestre Noza), ao contrário, recebe a encomenda de três grandes séries, sobre os temas da Via Crucis, dos Apóstolos e da Vida de Lampião. Ora, essa diferença de tratamento só pode ser explicada pela grande diferença de estilo entre os dois gravadores: enquanto o primeiro se esforça para gravar cuidadosamente todos os detalhes dos motivos representados (Figura 07 e o8), com linhas extremamente finas, o segundo se contenta em criar imagens extremamente simples, bastante "primitivas", gravadas sem nenhum refinamento, mesmo quando copiadas de fotografias (Figuras o9 e 10).

Figura o9 Folheto de cordel com zincogravura (fotografia): As grandes aventuras de Armando e Rosa conhecidos por "Côco Verde" e "Melancia", Juazeiro do Norte, Filhas de J. Bernardo da Silva, 1976, c. $15 \times 11$ cm (col. Idelette Muzart, Paris).

Figura 10

Xilogravura de Mestre Noza realizada para folheto de amor não identificado, $9 \times 7 \mathrm{~cm}$ (col. Geová Sobreira, Brasília).
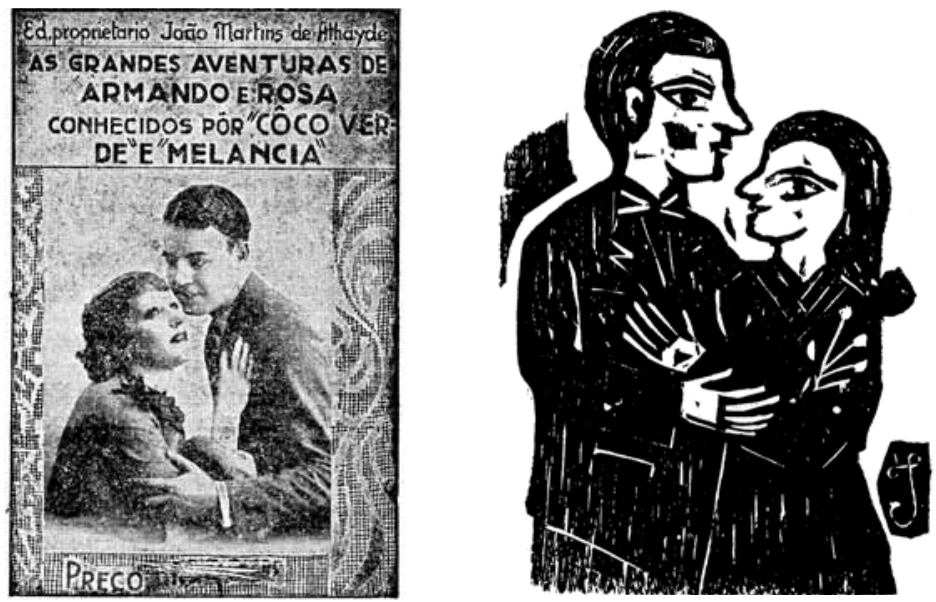

Enfim, a própria história de vida dos xilógrafos confirma que a arte de Mestre Noza foi efetivamente favorecida, em detrimento da de João Pereira da Silva. Em 1965, a Via Crucis gravada pelo primeiro é publicada na França, em forma de um álbum de 
luxo: esta publicação teria uma enorme repercussão, marcando uma nova fase na história da gravura popular e na vida de Mestre Noza, que subitamente se torna famoso no Brasil e no exterior. Para João Pereira da Silva, no entanto, a situação é exatamente contrária. Sem produzir novas obras, ele fica de fora do movimento de renovação da xilogravura do Ceará, caindo pouco a pouco no esquecimento. Não raro, inclusive, seu papel de pioneiro da gravura de cordel em Juazeiro do Norte é omitido, em favor justamente de Mestre Noza ${ }^{13}$. Assim, enquanto este recebe inúmeras homenagens em vida e mesmo depois de morto ${ }^{14}$, João Pereira da Silva vive seus últimos anos, e morre, no maior e mais injusto dos silêncios.

\section{Olhares folclóricos, visões regionalistas}

Se a apologia da técnica artesanal e das formas rústicas explica o sucesso de uma certa categoria de obras (a xilogravura estilizada) e o esquecimento de outras (a zincogravura e a xilogravura "naturalista"), é necessário explicar também as razões dessa própria apologia, a fim de se compreender o processo de legitimação artística da gravura popular em toda sua complexidade. Para isso, é preciso se colocar numa perspectiva mais ampla e analisar o contexto cultural e intelectual do Brasil de meados do século XX, quando o mundo letrado começa a se interessar pelas ilustrações de cordel e por outras categorias da arte popular.

Duas correntes ideológicas se destacam, então. A primeira é a erudição de tipo folclórico, que vive seus momentos de glória no país, com a constituição de um verdadeiro movimento organizado, muito vasto e ativo do final dos anos 1940 ao início dos anos $1960{ }^{15}$. O primeiro intelectual a se interessar pela gravura popular é, inclusive, um folclorista bastante implicado nesse movimento: Théo Brandão, secretário da Comissão Alagoana de Folclore, que tem a idéia de imprimir as ilustrações de cordel em folhas soltas, para expô-las durante a Semana Nacional de Folclore de Maceió, em 1952. Com o apoio dos poderes institucionais e da mídia, os folcloristas desempenham, assim, um papel fundamental, não somente na promoção, mas também na "proteção" das artes populares, em conformidade com a missão de salvaguarda que eles mesmos se dão.

Ora, as iniciativas que têm por objeto a gravura popular manifestam exatamente o que caracteriza as concepções e as atitudes de tipo folclórico: a admiração pelas coisas do passado,
13. Liêdo Maranhão de Souza, notadamente, em sua obra pioneira sobre as ilustrações de cordel, indica Mestre Noza como o mais antigo xilógrafo de Juazeiro do Norte, não fazendo nenhuma referência a João Pereira da Silva: cf. Souza (1981). Por consequência, os pesquisadores que reproduzem os dados deste autor cometem a mesma omissão: $c f$. Iglesias (1992) e Hata (1999).

14. Veja-se, por exemplo, as comemorações póstumas pelos 100 anos de Mestre Noza, pela Fundação Memorial de Padre Cícero, de Juazeiro do Norte, que incluiu a publicação de uma série de estudos sobre o artista: cf. Tavares (1997).

15. Sobre o movimento folclórico brasileiro, a obra de referência é Vilhena (1997). 
16. Sobre os significados profundos do movimento regionalista nordestino, aconselhamos a leitura de Albuquerque Júnior (1999). principalmente pelas técnicas artesanais, cujo desaparecimento é frequentemente anunciado, em razão do progresso técnicoindustrial; a idéia de que o mundo letrado pode - e até deve - evitar esse desaparecimento, tirando as obras ameaçadas de seu ambiente natural para integrá-las no circuito erudito de coleções, exposições e publicações; a preferência dada a certas categorias de obras, em detrimento de outras, em função de critérios preestabelecidos que sempre associam o "popular" ao manual, simples, primitivo, rústico, antinaturalista; a certeza, enfim, que o criador popular, sendo autodidata, é necessariamente ingênuo, e que seu anonimato é um valor positivo, ao contrário da afirmação individual expressa numa assinatura.

A outra corrente ideológica que ajuda a compreender o processo de legitimação da gravura popular está diretamente associada ao discurso folclorista. A partir dos anos 1920, intelectuais começam a exaltar as especificidades socioculturais do Nordeste, explicando-as com argumentos geográficos e históricos, como as secas periódicas e o fenômeno do cangaço. Assim, foram definindo uma região que teria ficado às margens do progresso, tornando-se o reservatório de tradições e costumes muito antigos, que remontariam à Idade Média. Por exemplo, a grande importância dos chefes políticos locais, os coronéis, leva alguns a identificar, na sociedade nordestina, uma estrutura de tipo feudal.

Essas teses servem, principalmente, para se colocar o Nordeste no centro das discussões nacionalistas: com suas tradições arcaicas e "primitivas", esta região é considerada a mais autêntica do Brasil, ao contrário do Sudeste, que teria pago o preço da "desnacionalização", incorporando modelos estrangeiros para desenvolver-se econômica e culturalmente. Sociólogos e escritores, pintores e políticos, nordestinos ou não, muitos contribuem, assim, para cristalizar a noção de um Nordeste essencialmente ligado ao passado e naturalmente avesso aos valores e práticas da modernidade. Um Nordeste, portanto, que seria o avesso de um grande centro como São Paulo, e isso, em detrimento das diversidades dessas duas zonas geográficas, sempre negligenciadas em favor de generalizações que passam do arcaico ao moderno, do rural ao urbano, do oral ao escrito, do artesanal ao industrial, do erudito ao popular ${ }^{16}$.

É nesse contexto que surge, a partir do final dos anos 1940, o interesse pela arte popular do Nordeste, em particular por aquelas categorias que - como a xilogravura rústica - servem para "pro- 
var" os anacronismos de um Nordeste constantemente associado à Idade Média e, mais ainda, a uma Idade Média por si só bastante estereotipada, já que considerada modelo de civilização "pura" e "autêntica", em oposição à civilização "capitalista" e "tecnicista" que surge com a Idade Moderna ${ }^{17}$.

Nesse sentido, é interessante notar a evolução no pensamento de um dos ícones da "inteligência" nordestina. Em 1952, quando ainda é um jovem escritor em começo de carreira, Ariano Suassuna associa a gravura popular à arte contemporânea e, em particular, à obra de artistas como Picasso, Gauguin, Chagall, Rousseau e Modigliani ${ }^{18}$. Para ele, o ponto de contato entre estas produções seria o primitivismo inerente à arte popular, e incorporado pela arte erudita do século XX, bem como uma "comunidade de intenções" entre artistas de culturas diferentes, no momento da criação:

O impulso artístico, suas soluções, seus caminhos são mais semelhantes em cada homem do que se pensa ordinariamente, assim como o pecado: resolve-se, em última análise, numa "vontade de fazer", anterior à obra, e num "isto é bom", a ela posterior. É aí que se encontram artista erudito e artesão popular (SUASSUNA, 1952, p.1).

A perspectiva muda completamente, no entanto, num texto do final dos anos 1960, quando Ariano Suassuna já se tornara um escritor famoso, inspirando-se da tradição ibérica e da literatura de cordel - também considerada uma "reminiscência medieval" - para criar um teatro "tipicamente nordestino":

Eu via reproduções de gravuras medievais européias e sentia nelas uma pureza, uma limpeza, uma força que faltavam à gravura da Renascença e à gravura moderna, apesar de muito mais elaboradas. [...] na gravura medieval mais primitiva, o que me agradava era o real transfigurado pelo poético, o real como mero ponto de partida, o achatamento geral da gravura pela ausência de profundidade, pela falta de claro-escuro e de perspectiva, assim como a predominância do traço limpo e puro e forte contornando as figuras. Ora, eram mais ou menos essas as características da nossa xilogravura popular (SUASSUNA, 196o, p.2).

Vê-se, portanto, que Ariano Suassuna muda de objeto de comparação, mas evoca exatamente os mesmos elementos plásticos que tinha utilizado em 1952, para associar a gravura popular à arte moderna: ausência de perspectiva e profundidade na ima-
17. Já há algum tempo que historiadores, como Georges Duby por exemplo, tentam combater os lugares-comuns em relação à Idade Média. Por outro lado, vale notar que a cultura medieval não pode ser considerada um bloco homogêneo: em outros estudos, tivemos a oportunidade de estudar as relações entre arte "erudita" e arte "popular" na França do século XIII - cf. Ramos (1998).

18. Para uma análise aprofundada das ideias de Ariano Suassuna sobre a gravura popular, $c f$. Ramos (2008a). 
gem, bem como o não-naturalismo das formas. Por que, então, prefere mudar de ponto de vista, passando a relacionar esta gravura a uma arte como a medieval, comumente associada ao arcaico, ao não moderno?

Esta questão resume toda a dimensão folclórica e regionalista do processo de promoção e legitimação artística da gravura popular. A nova atitude de Ariano Suassuna mostra que ele, assim como outros intelectuais de sua geração, foi condicionado a encarar a obra de arte popular - principalmente a realizada no Nordeste apenas como uma relíquia de uma idade remota, de uma época mítica e idealizada, berço de uma "pureza original" que teria se perdido em seguida, com os progressos da razão, do capital e da máquina - com a Modernidade, enfim. Daí a preferência pela xilogravura artesanal, rústica e primitiva, e o desprezo pelas outras categorias de ilustração de cordel, a zincogravura e a xilogravura refinada, que não se encaixam nas noções estabelecidas para "popular" e "nordestino", tanto por questões técnicas como estéticas.

Conclui-se, assim, que o processo de legitimação da gravura popular não significou apenas a criação de uma nova categoria artística. $\mathrm{Na}$ verdade, ao retirar as obras do mercado, para levá-las ao museu, os representantes da cultura acadêmica, oficial, fizeram bem mais do que tirar uma produção do anonimato, colocando-a no centro do palco da arte brasileira: eles também condenaram essa produção a desempenhar um papel bastante controverso, numa peça extremamente complexa, sobre a questão da identidade de um povo e de uma região.

\section{Referências bibliográficas}

(s.a.). Arte Brasileira em Portugal. Módulo. Revista de Arquitetura e Artes Visuais no Brasil. Rio de Janeiro, ano VIII, $n^{\circ} 28$, p. 49, março de .

(s.a.). Xilogravura Popular. Recife: Imprensa Universitária, 1965.

(s.a.). Xilogravuras Populares Alagoanas (Coleção Theo Brandão). Maceió: Imprensa Universitária/UFAL, 1973.

ALBUQUERQUE JÚNIOR, Durval Muniz de. A Invenção do Nordeste e Outras Artes. Recife/São Paulo: Fundação Joaquim Nabuco/Editora Massangana/Cortez Editora, 1999. 
DINIZ, Clarissa. Crachá: aspectos da legitimação artística (Recife-Olinda, 1997 a 2000). Recife: Fundação Joaquim Nabuco, Editora Massangana, 2008.

HATA, Luli. O Cordel das Feiras às Galerias. 1999. Dissertação (Mestrado em Teoria Literária) - Instituto de Estudos da Linguagem, Universidade de Campinas-UNICAMP, Campinas.

IGLESIAS, María Lucía Díaz Iglesias. Xilogravura Popular Brasileira: Iconografia e Edição. 1992. Dissertação (M em Artes), Escola de Comunicação e Artes, Universidade de São PauloUSP, São Paulo.

MACHADO, Lourival Gomes. Uma História de Leões. O Estado de SãoPaulo, São Paulo, 5 de março de 1960. Suplemento Literário, p. 6.

MACHADO, Lourival Gomes. O Leão Viaja. O Estado de SãoPaulo, São Paulo, 16 de dezembro de 1961. Suplemento Literário, p. 6.

RAMOS, Everardo. Traditions locales et art savant au XIIIe siècle : le décor monumentale de l'église de Chissey-sur-Loue. Histoiredel'Art. Paris:Association des professeurs d'archéologie et d'histoire de l'art des universités-APAHAU, 1998, p. 49-58.

RAMOS, Everardo. La gravure populaire au Brésil (XIXe-XXe siècle) : du marché au marchand. 2005. 2 vol. Tese (Doutorado em Estudos Brasileiros) - Université Paris X - Nanterre, Nanterre (França), 2005 (a).

RAMOS, Everardo. Du marché au marchand. La gravure populaire brésilienne. Gravelines (França): Musée du dessin et de l'estampe originale, 2005 (b).

RAMOS, Everardo. Ariano Suassuna e a gravura popular brasileira ou a (de)formação de um pensamento crítico. In: ZACCARA, Madalena; PEDROSA, Sebastião (orgs.). Artes visuais: conversando sobre. Recife: Ed. Universitária da UFPE, 2008 (a).

RAMOS, Everardo. Ilustrações de Folhetos de Cordel: o Romance dos Esquecidos ou a Peleja do Popular com o Moderno. In: NEMER, Sylvia (org.). Recortes contemporâneos sobre o cordel. Rio de Janeiro: Edições Casa de Rui Barbosa, 2008 (b). 
SOUZA, Liêdo Maranhão de. O Folheto Popular. Sua Capa e seus Ilustradores. Recife: Fundação Joaquim Nabuco, Editora Massangana, 1981.

SUASSUNA, Ariano. A Gravura na Arte Popular. Diário de Pernambuco, Recife, p.1, 15 de junho de 1952.

SUASSUNA, Ariano. Xilogravura Popular do Nordeste. Jornal Universitário, Recife, agosto de 1969.

TAVARES, Íris (org.). Cem anos de Mestre Noza. Arte que o tempo não sucumbiu. Juazeiro do Norte, Fundação Memorial de Padre Cícero, 1997.

VILHENA, Rodolfo.Projeto e Missão. O Movimento Folclórico Brasileiro (1947-1964). Rio de Janeiro: Funarte/Fundação Getúlio Vargas, 1997 


\section{EVERARDO RAMOS}

É historiador da arte, formado pela Université de Franche-Comté (França). Possui Mestrado pela mesma universidade e Doutorado pela Université Paris X - Nanterre (França), onde defendeu uma tese sobre a gravura popular brasileira. É autor de Du marché au marchand. La gravure populaire brésilienne, catálogo da exposição apresentada no Musée du Dessin et de l'Estampe Originale de Gravelines (França, 2005), de que também foi curador. É Professor Adjunto e Coordenador do Curso de Artes Visuais da Universidade Federal do Rio Grande do Norte, em Natal.

E-mail: everardoramos@gmail.com 